соискатель кафедры социологии и управления Белгородского государственного

технологического университета им. В.Г. Шухова

\section{СТРАТЕГИЧЕСКИЕ НАПРАВЛЕНИЯ АНТИТЕРРОРИСТИЧЕСКОГО СОТРУДНИЧЕСТВА ГОСУДАРСТВ - УЧАСТНИКОВ СНГ}

\section{Аннотация:}

В статье выделены и рассмотрены стратегические направления антитеррористического сотрудничества государств - участников СНГ: нормативно-правовое обеспечение (присоединение к основным международным договорам, принятие международных правовых актов в рамках СНГ, гармонизация национального законодательства государств-участников), информационное обеспечение (получение прогнозной информации, противодействие терроризму в сфрере применения новых ITтехнологий, совершенствование правового регулирования информационного обмена), кадровое обеспечение (усиление требований к отбору и повышению квалификации специалистов по противодействию международному терроризму).

Ключевые слова:

терроризм, стратегия, антитеррористическое сотрудничество, государства - участники СНГ, нормативно-правовое обеспечение, информационное обеспечение, кадровое обеспечение.
PhD applicant, Sociology and Management Department, Belgorod State Technological University named after V.G. Shukhov

\section{STRATEGIC DIRECTIONS OF ANTI-TERRORIST COOPERATION OF THE CIS MEMBER STATES}

Summary:

This article reviews the strategic directions of the antiterrorist cooperation of the CIS member states. They are regulatory support (accession to the main international agreements, acceptance of international legal acts within the CIS, harmonization of the national legislation of the CIS member states); strategic communication (obtaining predictive information, counter-terrorism efforts in the sphere of new IT technologies application, improvement of the legal regulation of information exchange); staff assistance (strengthening the requirements for selection and career enhancement in actions against international terrorism).

Keywords: terrorism, strategy, anti-terrorist cooperation, CIS member states, regulatory support, strategic communication, staff assistance.

Имеется целое множество понятий, в которое входит компонент «стратегия»: стратегический план, стратегическое управление, стратегическое развитие, стратегическая деятельность, стратегическое мышление. М. Мескон, М. Альберт и Ф. Хедоури утверждают, что стратегия - это детальный всесторонний комплексный план, предназначенный для того, чтобы обеспечить осуществление миссии организации и достижение ее целей [1, с. 257].

Применительно к стратегическому управлению антитеррористическим сотрудничеством (АТC) обычно выделяют и рассматривают два уровня: 1) стратегическое управление АТС на глобальном уровне, 2) стратегическое управление АТС на субрегиональном уровне [2].

Глобальная стратегия развития международного антитеррористического сотрудничества разработана и изложена в Итоговом документе Всемирного саммита 2005 г. (резолюция 60/1 Генеральной Ассамблеи) государств - членов Организации Объединенных Наций [3]. В этом документе определены следующие основные элементы (принципы, направления) данной стратегии:

1) убеждать группы в необходимости отказаться от терроризма или его поддержки;

2) лишить террористов доступа к средствам для совершения нападения;

3) удерживать государства от поддержки террористических групп;

4) укреплять потенциал государств по предотвращению терроризма;

5) защищать права человека в контексте терроризма и контртерроризма.

В данной статье рассматривается стратегическое управление ATC на субрегиональном уровне, точнее на уровне взаимодействия государств - участников СНГ. В научной литературе, в том числе зарубежной, выделяется несколько стратегий антитеррористической политики государств и их объединений: предупредительная, охранительная, стратегии контроля, сдерживания, жесткого подавления [4].

По мнению опрошенных нами экспертов и сотрудников органов противодействия терроризму, в настоящее время для государств - участников СНГ наиболее предпочтительна предупредительная стратегия (на это указали соответственно 65,0 и 47,2 \% опрошенных). Сравнительно ниже оценены альтернативные стратегии: контроля $(10,4$ и 12,2), жесткого подавления наиболее опасных форм $(10,4$ и 13,9), охранительная $(10,0$ и 10,0), сдерживания $(5,0$ и 7,8 \%) (интервью-опрос 2014 г.) [5]. 
В стратегии оптимизации антитеррористического сотрудничества выделим три управленческих аспекта: 1) принципы стратегического управления, 2) направления стратегического управления, 3) барьеры, препятствующие эффективному управлению АТС.

В статье предлагается рассмотрение одного аспекта - направлений стратегического управления. Анализ практики организации международного сотрудничества, осуществляемой Антитеррористическим центром (АТЦ) СНГ, личный опыт участия в этой деятельности дают основания для выделения трех стратегических направлений сотрудничества: нормативно-правовое, инфрормационное, кадровое обеспечение.

В рамках нормативно-правового обеспечения АTC целесообразно выделить три приоритетных поднаправления.

Во-первых, присоединение в области борьбы с международным терроризмом к основным договорам, которые заключены в рамках $\mathrm{OOH}$, а также ее специализированных учреждений и МАГАТЭ. В резолюции Совета Безопасности ООН № 1373 отмечается актуальность данной проблемы, и на сегодняшний день в государствах Содружества сделано многое в этом направлении. Так, «полностью ратифицированы 12 антитеррористических конвенций ООН государствами участниками СНГ. К их числу относятся: Международная конвенция о борьбе с финансированием терроризма, Международная конвенция о борьбе с захватом заложников, Конвенции о борьбе с незаконными захватами воздушных судов и с незаконными актами, направленными против безопасности гражданской авиации, Конвенция о предотвращении и наказании преступлений против лиц, пользующихся международной защитой, в том числе дипломатических агентов и другие конвенции» [6, с. 187].

Как уже отмечалось, актуальное значение в связи с этим приобретает имплементация норм международного права в национальном законодательстве: «очень актуальной» эту проблему считают 10 \% экспертов; 45 \% признают ее «достаточно актуальной»; то, что данная проблема «скорее актуальна, чем нет», полагают 25 \% экспертов; «скорее неактуальна» - 15 \%; находят ее неактуальной 5 \% экспертов (экспертный опрос 2016 г.).

В перспективе необходимо дальнейшее углубление сотрудничества государств в рамках универсальных конвенций. Следовательно, не только не утрачивается актуальность работы в данном направлении, но и растет необходимость ее продолжения. В связи с этим важно понимать и учитывать, что мешает решить проблему имплементации правовых норм. В числе таких помех эксперты назвали: недооценку важности данной проблемы и необходимости ее разрешения (40\%), трудности координации усилий государств - участников СНГ (35), организационнопроцедурные трудности (30), значительный разрыв между нормами национальных законодательств государств - участников СНГ (25), неоднозначное толкование базовых понятий (20), дефицит компетентных кадров (5 \%) (экспертный опрос 2016 г.).

Тем не менее мы полагаем, что принятие Всеобщей конвенции по борьбе с терроризмом, над которой работает ООН, позволит решить многие проблемные вопросы правового регулирования взаимодействия и сотрудничества государств в области борьбы с террористической деятельностью. За принятие такой конвенции высказались практически все опрошенные эксперты (90\%).

Во-вторых, немаловажный вектор совершенствования нормативно-правовой базы в области борьбы с террористической деятельностью направлен на разработку и принятие правовых актов международного характера по вопросам взаимодействия и сотрудничества государств в рамках борьбы с террористической деятельностью. Важность работы в данном направлении определяется тем, что универсальные конвенции не охватывают всего спектра проблем в сфере борьбы с терроризмом, не всегда учитывают специфические этнические, национальные и религиозные особенности. Следовательно, актуализируется необходимость разработки и принятия соответствующих межгосударственных документов на региональном уровне, расширяющих правовые механизмы сотрудничества государств. Антитеррористический центр принял непосредственное участие в разработке пакета актов и документов, которые регламентируют вопросы обеспечения защиты секретной информации органов СНГ. Они вступили в действие в 2013 г. Указанный пакет документов являет собой непременное условие последующего заключения государствами СНГ Соглашения касательно обмена информацией по вопросам борьбы с террористической деятельностью. Его проектом предусмотрен обмен информацией, в том числе секретного характера.

В-третьих, еще один приоритетный вектор совершенствования антитеррористического законодательства включает в себя возможность решения проблем гармонизации национального законодательства государств - участников СНГ. Все страны Содружества приближаются к пониманию того очевидного факта, что успешное противостояние терроризму возможно только на платформе конструктивного взаимодействия, в основе которого лежит однородное правовое поле. Данные проведенного экспертного опроса подтверждают актуальность этого вопроса. Однородность правового поля по антитеррористическому сотрудничеству государств СНГ на настоящий момент времени отмечает только треть опрошенных. Практически половина экспертов 
(45 \%) отрицательно ответила на поставленный вопрос (варианты ответов «нет» / «скорее нет»). При этом каждый пятый эксперт затруднился оценить однородность/неоднородность правового поля. Поэтому неудивительно, что подавляющее большинство экспертов (80 \%) подчеркивает важность обеспечения однородности правового поля (экспертный опрос 2016 г.).

В завершении характеристики нормативно-правового обеспечения АТС следует обратиться к результатам экспертного опроса касательно направлений, рассмотренных выше, которые, по мнению экспертов, представляются наиболее актуальными на сегодняшний день (экспертный опрос 2016 г.):

- гармонизация национального законодательства стран - участников СНГ (70 \% экспертов);

- разработка и принятие международных правовых актов в рамках СНГ (40\%);

- присоединение к действующим международным договорам в области борьбы с террористической деятельностью (15\%).

Переходя к характеристике направления информационного обеспечения АТС, обратимся предварительно к результатам экспертного опроса относительно необходимости совершенствования информационного взаимодействия в сфере борьбы с терроризмом (экспертный опрос 2014 г.). Эксперты указывают на следующие фракторы актуализации разработки данного направления. Это необходимость:

- получения прогнозной информации (53,3 \%);

- противодействия использованию новых IT-технологий в подготовке террористической деятельности $(46,7)$;

- знания новых информационных ресурсов и инструментов, которые используются при подготовке и совершении терактов $(33,3)$;

- совершенствования правового регулирования информационного обмена в сфере борьбы с террористической деятельностью (20,0 \%).

С учетом результатов экспертной оценки определены основные направления совершенствования информационного взаимодействия государств - участников СНГ, к числу которых относятся:

- разработка действенной системы нормативно-правового регулирования информационного обмена;

- продуктивное применение межгосударственных информационных систем коллективного пользования;

- информационное обеспечение системы межгосударственного розыска;

- использование в режиме онлайн гипертекстового портала АТЦ СНГ;

- применение абонентских пунктов различного рода информационных систем коллективного пользования;

- обсуждение вопросов антитеррористической деятельности в рамках научно-практических конференций различного уровня, совместное консультирование заинтересованных сторон;

- активизация продуктивного взаимодействия, сотрудничества, а также информационного обмена с другими международными организациями, которые участвуют в борьбе с терроризмом;

- увеличение и расширение информационных контактов с отраслевыми структурами СНГ по борьбе с терроризмом;

- активное использование информационного потенциала командно-штабных учений и тренировок;

- активизация информационного взаимодействия с параллельными структурами, которые действуют на постсоветском пространстве (РАТС, ШОС и ОДКБ) [7, с. 188-189].

Еще одно стратегическое направление оптимизации АТС - его кадровое обеспечение. Противодействие экстремистской и террористической деятельности представляет собой ту сферу, в которой сотруднику для осуществления профессиональной деятельности потребуется определенный жизненный опыт, опыт специализированной оперативной работы, исключительные профессиональные навыки, знания в сфере теологии и тенденций эволюции традиционных религий, знания истоков возникновения и распространения религиозного фундаментализма, возникновения сект и прочих деструктивных организаций, которые прикрываются догмами религии.

Следовательно, исходя из перечисленных выше составляющих, оптимальный возраст специалиста подразделения по борьбе и противодействию экстремистской деятельности - 30-35 лет. Определяемый нами возрастной ценз в первую очередь связан с набором характеристик, которые специалист указанного подразделения должен иметь для работы в рассматриваемой сорере. Важен жизненный опыт будущего сотрудника, он должен пройти путь личностного духовного становления, иметь знания в области политической системы государства, общественного устройства, взаимоотношений государства и религии.

С целью уточнения требований к подготовке и повышению квалификации специалистов участников международной антитеррористической деятельности был проведен опрос экспертов 
(экспертный опрос 2015 г.). Им было предложено оценить по пятибалльной шкале важность качеств, которые должны быть присущи данной категории специалистов: профессиональные умения и навыки (оценка - 4,6 балла), профессиональные знания $(4,2)$, опыт оперативной работы $(4,2)$, морально-психологическая подготовка (4), физическая подготовка $(3,8)$, социальная компетентность $(3,8)$, социокультурная компетентность (знания по религиоведению и т. д.) $(3,8)$, достаточный жизненный опыт (3,6 балла).

По мнению большинства экспертов, необходимо предъявить следующие требования к сотрудникам подразделений по противодействию терроризму и экстремизму, поступающим на работу:

- прохождение службы в оперативных подразделениях низового уровня;

- пятилетний стаж оперативной работы;

- обязательное прохождение курсов переподготовки и повышения профессионального уровня.

Более того, сотрудник подразделения по противодействию экстремистской и террористической деятельности должен иметь свое собственное вероубеждение, четко сформированное отношение к религии. Он должен не только обладать глубокими познаниями в сфере избранной религии, но и разбираться в тенденциях развития других религиозных конфессий.

В силу специфики задач, решаемых подразделениями по противодействию экстремизму и терроризму, необходим опыт оперативной работы. Сотрудник, который начал работу в низовых территориальных подразделениях, к 30-35 годам уже имеет достаточный опыт в сфере оперативной работы, сложившиеся и закрепленные профессиональные знания, навыки и умения.

Объект воздействия специалистов подразделения по противодействию экстремистской деятельности - это необычные малограмотные преступники, которые совершают уголовные преступления. Основной контингент их воздействия представляют лидеры и члены террористических и экстремистских организаций. А эти люди как раз обладают высоким интеллектом, богатым жизненным опытом, глубокими знаниями теологии, имеют психофизиологические особенности.

Согласно изложенному, считаем целесообразным осуществлять прием на работу специалистов указанных подразделений из числа тех лиц, которые прошли службу в низовых оперативных подразделениях и имеют стаж оперативной работы не менее 5 лет. В случае перевода сотрудника из других подразделений целесообразно предусмотреть обязательное прохождение таковыми курсов, направленных на переподготовку и повышение профессионального уровня. Курсы переподготовки будущих сотрудников подразделений в обязательном порядке должны ознакомить их с нормативно-правовой основой противодействия терроризму, включая международный опыт противодействия террористической деятельности; предоставить сведения о террористических и экстремистских организациях, которые признаны судом и запрещены на территории государств - участников СНГ, их лидерах и активных адептах запрещенных структур; ознакомить с перечнем экстремистских и террористических организаций, которые запрещены на территориях государств - участников СНГ, ШОС и ОДКБ, а также входят в перечень экстремистских и террористических организаций, составленный ООН.

На наш взгляд, «специально созданные межгосударственные структуры, такие как Антитеррористический центр государств - участников СНГ, Бюро по координации борьбы с организованной преступностью государств - участников СНГ, Антитеррористическое подразделение штаб-квартиры ОБСЕ, Региональная антитеррористическая структура ШОС, а также структуры в других государствах могли бы оказать содействие в подготовке специалистов по борьбе с экстремизмом и терроризмом» [8, с. 192].

Важным является, чтобы сотрудники подразделений противодействия экстремистской и террористической деятельности продолжали свой карьерный рост лишь только в пределах данного подразделения. Как показывает практика, практическая подготовка одного полноценного и квалифицированного специалиста в указанной области занимает минимум 3-4 года. Более этого, подготовка профессионала в данной области является достаточно затратной. Специалисты подразделений по противодействию экстремизму и терроризму по линии противодействия экстремизму и терроризму стажируются, как правило, в компетентных органах зарубежных государств, обучаются и проходят тренинги с экспертами и специалистами международных структур, поэтому как минимум нецелесообразно после получения профессиональных квалифицированных навыков и знаний в сфере противодействия террористической и экстремистской деятельности применять и использовать их в работе в других подразделениях, которые не связаны с данного рода деятельностью. Также представляется нецелесообразным проводить ротацию руководителей и сотрудников данного подразделения с другими подразделениями.

Степень востребованности дополнительных знаний и навыков по отдельным направлениям повышения квалификации кадров выяснялась в ходе проведения экспертного опроса 2014 г. (табл. 1). 
Таблица 1 - Приоритетные направления подготовки и повышения квалификации кадров АТС

\begin{tabular}{|l|c|c|}
\hline \multicolumn{1}{|c|}{ Направление } & $\begin{array}{c}\text { Ранговое } \\
\text { место }\end{array}$ & $\begin{array}{c}\text { Частота } \\
\text { выбора, \% }\end{array}$ \\
\hline Прогнозирование ситуаций в сфере противодействия терроризму & 1 & 61,1 \\
\hline Организация обмена инфрормацией & 2 & 44,4 \\
\hline Организация совместной деятельности & 3 & 38,9 \\
\hline Анализ ситуаций в сфере противодействия терроризму & 4 & 27,8 \\
\hline Организация обучения и повышения квалификации кадрового состава & 5 & 16,7 \\
\hline Применение программно-целевого метода & $6-8$ & 11,1 \\
\hline Разработка тактических планов и мероприятий & $6-8$ & 11,1 \\
\hline Организация информационного обеспечения совместных действий & $6-8$ & 11,1 \\
\hline
\end{tabular}

Следует обратить внимание на то, что почти две трети экспертов выделяют «прогнозирование ситуаций в сорере противодействия терроризму» в качестве приоритетного направления подготовки и повышения квалификации кадров АТС.

Подводя итоги проведенного анализа, выделим наиболее существенное в стратегических направлениях антитеррористического сотрудничества государств - участников СНГ: по нормативно-правовому обеспечению - присоединение к основным договорам в области борьбы с международным терроризмом, разработка и принятие международных правовых актов по вопросам антитеррористического сотрудничества в рамках СНГ, гармонизация национального законодательства государств - участников СНГ; по инфоормационному обеспечению - получение прогнозной информации, противодействие использованию новых IT-технологий в подготовке террористической деятельности, совершенствование правового регулирования информационного обмена в сфере борьбы с терроризмом; по кадровому обеспечению - предъявление повышенных и дифференцированных требований к поступающим на работу сотрудникам подразделений по противодействию терроризму и экстремизму, к прохождению ими службы и их карьерному росту.

\section{Ссылки и примечания:}

1. Мескон М., Альберт М., Хедоури Ф. Основы менеджмента. М., 1998.

2. Гридчин А.А., Пашкевич А.В. Стратегическое управление международным антитеррористическим сотрудничеством на глобальном уровне // Диагностика и прогнозирование социальных процессов : материалы междунар. науч.-практ. конф. : в 2 ч. Белгород, 2016. Ч. 1. С. 80-85.

3. Единство в борьбе с терроризмом: рекомендации по глобальной контртеррористической стратегии : доклад Генерального секретаря от 27 апр. 2006 г.

4. Шикунов Д.М. Система противодействия терроризму в Российской Федерации // Власть. 2014. № 8. С. $190-194$; Hudson R.A. The sociology and psychology of terrorism: who becomes a terrorist and why? Honolulu, 2005 ; Nacos B.L. Mass-mediated terrorism: the central role of media in terrorism and counter terrorism. 2nd ed. Lanham, 2007. $264 \mathrm{p}$.

5. Статья подготовлена по результатам социологических опросов, проведенных автором среди руководителей и сотрудников правоохранительных органов и специализированных служб государств - участников СНГ по противодействию терроризму: «Система управления международным антитеррористическим сотрудничеством в постсоветском пространстве» (2014 г., опрошено 180 респондентов и 18 экспертов); «Повышение готовности сотрудников правоохранительных органов и служб безопасности к проведению успешной антитеррористической деятельности» (2015 г., опрошено 160 респондентов и 15 экспертов); «Совершенствование нормативно-правового обеспечения международного антитеррористического сотрудничества» (2016 г., опрошено 20 экспертов).

6. Гридчин А.А., Пашкевич А.В. Управление международным антитеррористическим сотрудничеством. М., 2016. 272 с.

7. Там же. С. $188-189$

8. Там же. С. 192

\section{References}

Gridchin, AA \& Pashkevich, AV 2016a, Management of international antiterrorist cooperation, Moscow, 272 p., (in Russian). Gridchin, AA \& Pashkevich, AV 2016b, 'Strategic management of international antiterrorist cooperation at the global level', Diagnostika i prognozirovaniye sotsial'nykh protsessov: materialy mezhdunar. nauch.-prakt. konf., in 2 parts, Belgorod, part 1, pp. 80-85, (in Russian).

Hudson, RA 2005, The sociology and psychology of terrorism: who becomes a terrorist and why?, Honolulu.

Meskon, M, Albert, M \& Hedouri, F 1998, Fundamentals of management, Moscow, (in Russian). 264 p.

Nacos, BL 2007, Mass-mediated terrorism: the central role of media in terrorism and counter terrorism, 2nd ed., Lanham,

Shikunov, DM 2014, 'System of counteracting terrorism in the Russian Federation', Vlast', no. 8, pp. 190-194, (in Russian). Uniting against terrorism: recommendations for a global counter-terrorism strategy: Report of the Secretary-General 2006, 27 April, (in Russian). 